\title{
Culture Theory: The Developing Synthesis from Biology
}

\author{
Mark V. Flinn ${ }^{1}$ and Richard D. Alexander ${ }^{2}$
}

\section{INTRODUCTION}

This paper was invited as a discussion and critique of the preceding four papers. We have used it to take up the issue of whether the seemingly disparate approaches to culture theory from modern evolutionary biology can be reconciled and unified, and if so, how it can be done. Some of the differences, we think, exist chiefly in the minds of the investigators, perhaps as aspects of professional competition; some may arise from underlying ideological differences; and still others are apparently semantic. A few differences remain, however, that can be resolved only by showing that someone is wrong.

All four papers are efforts to analyze the mechanisms of cultural transmission and change. This development is a logical next step in the progress toward understanding the meaning of recent advances in evolutionary biology for the problem of culture, and in the actual analysis of culture. It is appropriate that the initial question asked by this new wave of culture theorists was: Is culture "adaptive" in the new sense of that term from biology? We believe that the answer to this question has been established as affirmative in a sufficiently general sense to show that the new theories from biology are on the right course (e.g., Alexander, 1977, 1979a; Cavalli-Sforza and Feldman, 1981; Chagnon, 1979, 1981; Daly and Wilson, 1978, 1981; Dickemann, 1979, 1981; Durham, 1976-1981; Flinn, 1981; Hames, 1979; Irons, 1979a, 1979b, 1981; Lumsden and Wilson, 1981). We hope that our comments here, while deliberately critical, will be recognized as part of the same general approach adopted by all of the authors represented in the four papers we are discussing, as well as those

'Department of Anthropology, Northwestern University, Evanston, Illinois.

${ }^{2}$ Museum of Zoology, University of Michigan, Ann Arbor, Michigan. 
listed above. The kinds of disagreements occurring now among biologists with regard to culture theory are not the sort that tend to cast doubt on the whole approach but, rather, are likely to produce new levels of accuracy and comprehension.

We will argue here that the dichotomy of cultural vs. biological (or even cultural as distinct and independent of biological) evolution, tacitly or explicitly accepted in all four papers in this volume and by other proponents of what is usually called the coevolutionary perspective (e.g., Bonner, 1980; Cloak, 1975; Dawkins, 1976; Mundinger, 1980; Pulliam and Dunford, 1980; Ruyle, 1973), is inappropriate and misleading. We believe that the culture-biology dichotomy derives from continued misunderstanding and misstatements of certain aspects of biological theory, namely:

1. "Genetic determinism" is often falsely attributed to all so-called "natural selection models" of culture. Apparently this is done because natural selection as a cause is restricted to cases involving genetic variation, and insufficient attention is given to the cumulative effects of past selection in producing biases that determine directions of cultural change generation after generation in the absence of relevant genetic change.

2. Cultural behaviors are inappropriately distinguished from other aspects of the phenotype on the basis of supposedly distinct and independent modes of transmission, usually stated as learned vs. genetic. In fact, the alternative to cultural behavior is not "genetically transmitted" behavior: the environment always participates in ontogenesis, even when it is invariable. Plasticity is the rule rather than the exception for all aspects of phenotypes, and imitation and other learning by observation are not restricted to human culture.

3. Theories pertaining to the levels of natural selection (e.g., Williams, 1966; Lewontin, 1970; Alexander and Borgia, 1978) are frequently misinterpreted with respect to egoistic vs. apparently groupbeneficial or altruistic behavior. In cases seemingly interpretable as evolved group-beneficial behavior several alternatives need to be eliminated, such as nepotism, reciprocity, and temporary commonality of interest.

4. Theories of nepotistic (Hamilton, 1964) and reciprocal (Trivers, 1971) altruism are frequently misinterpreted or neglected in refutations of biological analyses of culture. For example, it is sometimes forgotten that correlations of amounts and kinds of social interactions with genetic relatedness could have caused the evolution of (i.e., could be the evolved proximate mechanisms for) particular tendencies and biases in social learning, such as (a) assisting and (b) accepting the advice of close associates who, at least historically, are likely to be genetic relatives.

We believe that the resolution of the cultural-biological dichotomy hinges on understanding the evolution of social learning as the proximate mechanism of culture change. Because some of the above misunderstandings are at least partially rooted in historical traditions in social theory, we briefly review these traditions as they relate to models of 


\title{
THE "SUPERORGANIC" AS FORERUNNER OF COEVOLUTIONARY VIEWS
}

The social sciences have traditionally maintained the notion of culture as a unique phenomenon, above and beyond the organic world, possessing its own emergent properties (e.g., Kroeber, 1917; Parsons, 1954; Sahlins, 1976b). White (1949: xviii) summarizes this position as follows:

\begin{abstract}
With the advance of science . . . came a recognition of culture as a distinct class of events, as a distinct order of phenomena. It was seen that culture is not merely a reflex response to habitat, nor a simple and direct manifestation of "human nature." It came to be realized that culture is a continuum, a stream of events, that flows freely down through time from one generation to another and laterally from one race or habitat to another. One came eventually to understand that the determinants of culture lie within the stream of culture itself; that a language, custom, belief, tool or ceremony, is the product of antecedent and concomitant cultural elements and processes. In short, it was discovered that culture may be considered, from the standpoint of scientific analysis and interpretation, as a thing sui generis, as a class of events and processes that behaves in terms of its own principles and laws and which consequently can be explained only in terms of its own elements and processes. Culture may thus be considered as a selfcontained, self-determined process; one that can be explained only in terms of itself.
\end{abstract}

White's remarks have several implications, sometimes paralleled in modern coevolutionary theories. First, he is clearly attempting to separate the nature and mechanisms of culture from its biological underpinnings. There are three possible reasons for doing this: (1) biology (as a science dealing with genetics, physiology, and behavior) had not offered satisfactory and general explanations (this was the case); (2) explanations from outside biology had developed which were clearly sufficient (this was not the case); or (3) it had been shown that biology had no possibility of explaining culture (this also was not the case). If White had been writing more recently he might have followed the common but unsupportable and misleading practice of contrasting the terms "cultural" and "biological," with the latter meant to be synonymous with "genetic."

Second, White notes that the historical element in culture is so complex, and so important in determining its subsequent possible directions, that to try to understand the structure of culture in any place and time without taking its antecedents into account would be folly. While we agree, we also note that biologists have long recognized that this is true of all aspects to life: For each generation, organic evolution is restrained massively by its necessity of beginning with the attributes of the previous generation.

Despite White's confident statement, no superorganic theory of culture (or any other!) has yet found general aceptance. Superorganic theories have fallen short in part because, although they may include clear statements of the goals of cultural change, the mechanisms of change are obscure. The structuralists in anthropology, for example, contend that social "solidarity" (Durkheim, 1938) is the desired outcome of cultural 
by which cultural traits might come to prevail because of their contribution to solidarity, however, are not specified (but see Irons, 1981). White's $(1949,1959)$ theory of cultural evolution toward increased efficiency of energy utilization is similarly vague concerning the particular mechanisms that would result in such change, and why these mechanisms should come to characterize culture.

Specifying the mechanisms of cultural change, or the processes by which cultural traits are generated, saved, and lost, is a critical aspect of culture theory. Failure to specify such mechanisms has made superorganic theories difficult to test empirically. The lack of testable predictions has led many superorganic theorists to seek nonfunctional explanations of culture in terms of arbitrarily assigned sets of meanings or symbolizations (Sahlins, 1976b; Schneider, 1972) and to reject the possibility of a heuristic theory of culture. Indeed, this problem has led some culture theorists from within social anthropology to deny that culture can be reduced or dissected analytically at all.

Two important arguments are traditionally mustered against the notion of culture as a nonfunctional superorganic process with no biological underpinnings: (1) Humans are, after all, biological organisms and devote considerable effort and time to satisfying biological requirements such as acquiring energy and mates and producing offspring. The importance of this fact for explaining cultural diversity is recognized, for example, in ethnographic analyses of technological adaptations to different environments. (2) There is no reason to doubt that the capabilities for cultural acquisition and retention are evolved capabilities; consequently culture must have been biologically adaptive throughout human evolutionary history or the capacity for culture would not have evolved. Recognition of these arguments led to renewed efforts by anthropologists in the last two decades to explain culture in terms of adaptation to the environment (e.g., Steward, 1955; Rappaport, 1968; Vayda, 1968; Harris, 1975; Winterhalder and Smith, 1981), an approach with significant influences on current coevolutionary theories of cultural change.

\section{ENVIRONMENTAL DETERMINISM AND ECOLOGICAL THEORIES OF CULTURE}

The materialist and cultural ecology paradigms in anthropology involve explanations of culture in terms of group or population-level adaptation to the environment. A central theme of this perspective is the notion that an important function of culture is to regulate population density in response to the availability of certain critical resources, such as protein (Harris, 1975; Rappaport, 1968)-i.e., to achieve and maintain 
human populations at the "carrying capacity" of the environment. A selective mechanism for this process of group adaptation is proposed by Marvin Harris:

As in the case of other adaptive evolutionary novelties, groups that invented or adopted growth cutoff institutions survived more consistently than those that blundered across the limits of carrying capacity (1974:66).

This "group-selection" rationale is similar to that accepted by biologists (e.g., see Wynne-Edwards, 1962) prior to Williams' (1966) critique. To account for any degree of cultural complexity and diversity, however, Harris' mechanism calls for frequent extinction of human groups as a result of resource depletion. We are aware of no evidence that this kind of extinction has ever occurred. The context in which differential group extinction and proliferation is easiest to visualize-direct intergroup competition and aggression - is for some reason avoided by most authors who invoke group selection, including Harris, and Richerson and Boyd (this volume).

\section{THE NEW COEVOLUTION}

Largely in response to the so-called sociobiology debate, a number of authors have proposed that cultural evolution is an autonomous or separate adaptive process not leading to biological adaptation as such, but involving feedback between two separate kinds of adaptation, cultural and biological. Mundinger (1980: 197) aptly summarizes this coevolutionary perspective, which with certain exceptions (see below) typifies the approach of all of the preceding four papers in this volume:

Biological and cultural evolution are not the same process, nor is one an aspect of the other. They are independent mechanisms of change, and they explain change in fundamentally different forms of organized matter-life in one instance and culture in the other. Biological evolution describes and explains change in populations of organisms, and ultimately it explains change in the gene pools of those organisms. Cultural evolution explains and describes change in the two populations associated with acquired, imitable behavior, that is, the overt [behavioral] and covert [mental] populations that characterize culture.

The primary reason why biological evolution is regarded by coevolutionary theorists as insufficient to explain culture seems to be the apparent independence of cultural change from genetic change, in the sense that cultural traits are imitated and adopted by individuals in the absence of any immediate genetic change. Thus, Durham (this volume, p. 299) writes:

The full explanation of human diversity requires attention to both biological and cultural processes. The sociobiology debate has served to emphasize that although the Darwinian process of natural selection has been the major architect of biological influences on human diversity it is clearly not the mechanism directly 
responsible for molding the cultural influences. Cultural evolution can occur long before there appear changes in gene frequency in a population, and it must therefore be recognized as a distinct though interacting process.

The transmission of cultural traits independently of the transmission of genes (the "dual inheritance" model of Richerson and Boyd, 1978; see also Cloak, 1975; Durham, 1979; Cavalli-Sforza and Feldman, 1981) is the linchpin of the coevolutionary rationalization for discriminating between cultural and biological evolution. Whereas cultural traits are transmitted by imitation and instruction, biological traits are said to be transmitted by genes. Natural selection is tacitly or explicitly rejected as a guiding force in cultural evolution on the argument that it accounts only for the differential transmission of genes.

We believe that this way of addressing the question of how culture changes, and how it assumes its overall forms and diversity, draws its proponents into confusing language and false dichotomies. First, biological traits are not transmitted by genes but by integrity in both the genes and the environment. It is axiomatic that in reproduction only genes and a little cytoplasm are transmitted directly. The new phenotype develops in response to both its genetic background and the particular environment in which it finds itself, and this development may include imitating behavior and other kinds of social learning on a large scale in a very wide variety of organisms. If the environment does not repeat itself the phenotype will not do so either, even in organisms without a hint of culture. Thus, all phenotypic traits, not just cultural traits, are transmitted indirectly.

Second, Durham asserts that natural selection is "clearly not the mechanism directly responsible for molding the cultural influences on human diversity" (emphasis added). The implications are that (1) natural selection is somehow responsible (indirectly?) for shaping culture and (2) its influence on culture is somehow less direct than its influence on noncultural attributes, or is qualitatively different.

It is essential to clarify this point, not only for the question of culture theory but to put to rest some common criticisms against the approach of modern evolutionary biology. These criticisms are most often leveled against sociobiology and its supposed genetic determinism, where they occasionally have had some merit (cf., Alexander, 1979b); but they are inappropriately directed against the main body of evolutionary biologists, or all who are concerned with the adaptive significance of traits. (Anyone who accepts the critical account of Gould and Lewontin, 1979, as typifying evolutionary biology will disagree. Gould and Lewontin, however, seem to be objecting mainly to the concept of optimality in separate traits. In general we agree with their caveats on this issue. As with Sahlins (1976a), however, they adopt the strategy of selecting the worst papers they can find and contending that their faults are typical, rather than the more usual 
scientific procedure of building by correcting the faults of what they regard as the best or most nearly correct works. Thus, they devote more space to a minor field experiment, repeated unsuccessfully by other investigators and already criticized by both Gould and other evolutionary biologists, than to any other example. Anyone who depends on their paper as a description of modern evolutionary biology will have a strange and narrow view of the discipline.)

Natural selection does two things, and only the first of these is explicitly acknowledged by most coevolutionary theorists as part of a natural-selection model of culture. This first effect of selection is that it sorts among genetic variations, causing some to spread and others to disappear. Apparently, what Durham means by "not directly responsible" is that most cultural variations are not known (or expected by some, including us) to correlate with relevant genetic variations. But this kind of indirectness is not restricted to culture or typical only of it. On the contrary, it is probably correct to say that most of the observable phenotypic variations that co-occur locally within species do not correlate with genetic variations; this is certainly a correct statement about behavioral variations (as compared to morphological and physiological variations) (Lumsden and Wilson, 1981, seem to have a different view and may regard genetic variation as more frequently underlying observed phenotypic variations than we do). In this sense natural selection would not be "directly" responsible for "molding" even noncultural influences on the behavior of animals in general. Coevolutionists, by their criteria for distinguishing cultural and biological evolution, often seem instead to be distinguishing phenotypes from genotypes.

The second effect of natural selection is that it accumulates genes with particular consequences in particular environments. Through this second effect, which is both poorly understood and neglected by students of human behavior, natural selection is responsible for molding both cultural and noncultural influences on diversity. The real questions with regard to culture theory are the extent to which these cumulative effects of natural selection influence rates and directions of cultural change, and how this influence is exerted. We regard it as a fact that such influence occurs, not only in the appearance, adoption, rejection, disappearance, spread, and persistence of cultural traits, but in the same kinds of change in all other traits of organisms. Probably all of the biologists discussing culture theory agree, but some of their arguments may mislead others into thinking that they do not. Some critics of evolutionary explanations based on biological adaptation argue that for any trait to be considered biologically adaptive and a product of selection, it is necessary first to demonstrate that variations in that trait with differing reproductive value correlate with genetic variations. This is obviously an inappropriate requirement. The 
effect of natural selection is to do away with such variations in the process of molding evolutionary adaptation; such variations should only be expected when (1) selection acts differently on different parts of the population or (2) the environment has recently changed (Lumsden and Wilson, 1981, may have a different view). Phenotypes-and behavior $a$ fortiori-are ways of adopting different strategies in different environments using the same sets of genes; and phenotypes are products of natural selection. Complex alternative phenotypic strategies correlated with genetic uniformity are not evidence against the efficacy of selection, but instead are evidence of a history of powerful selection involving unpredictability in environmental shifts or oscillations. The biological literature is filled with examples.

We cannot overemphasize the importance of this point for understanding the influence natural selection has had on the evolution of human learning, and consequently on cultural evolution. The ability to learn, and directional tendencies in learning of whatever sort, are surely products of natural selection. Learning must result from the action of genes that specify that the organism should develop in such a fashion as to be able to respond adaptively to any situation from some array of likely situations when the particular one that will eventuate cannot be identified far ahead of time. What has been favored by natural selection in general is the ability to respond adaptively to varying environmental conditions. The one-gene-forone-behavior canalization falsely attributed to natural-selection models of culture is a product of a narrow and erroneous view of organic evolution.

The differences among the various biological-evolutionary approaches to cultural change thus involve different views of (1) the evolution of learning and (2) whether or not the transmission of cultural traits via learning decouples culture from biological adaptation. Because Durham's paper is a general effort to develop coevolutionary theory, we devote much of the remainder of our argument to it. This attention should not be construed as criticism in itself, but as an acknowledgment that his arguments are the most general, and probably the most widely cited.

In attempting to deal with proximate mechanisms, Durham, like other coevolutionists, distinguishes "genetic transmission" from "cultural transmission." This dichotomy, however, is unacceptable because: (1) in discussing genetic transmission he includes (solely) phenotypic traits that appear not just because genes pass unchanged from generation to generation but also because environments are consistent between generations; and (2) in discussing cultural transmission he includes (solely) traits that appear not just because of environmental influences but also because of genetic integrity and a history of natural selection. Durham asserts that humans are different from other organisms because "diversity is 
a product of two sets of instructions of genes and culture." This is a common theme (Cloak, 1975; Boyd and Richerson, 1978; Lumsden and Wilson, 1981; others). However, two sets of instructions occur in the development of all traits of all organisms: genetic and environmental. No rationale has ever been advanced for regarding the influence of culture on the development and expression of behavior as other than a special subset of the environment. The remarkable persistence of such unsupportable dichotomies seems to attest primarily to the human reluctance to see ourselves as natural objects in the universe, subject, even if in a special way, to the same rules that govern all life.

(Incidentally, but not trivially, Durham's definition of inclusive fitness includes the commonly repeated error that it is measured by adding the reproductive success of relatives to the reproductive success of the individual being considered. As West-Eberhard (1975) clarifies, Hamilton (1964) defined and used the term quite differently, adding instead the effect of the individual's effort on its relatives' reproduction.)

Durham proposes what he calls constrained microevolution as a general framework for cultural analysis; but, as we have already noted, all microevolution is always constrained. He argues, "both that the means of transmission are distinct from genetics and that the units transmitted are nongenetic entities [and] ... In this way, some aspects of human phenotypes may change wholly independently from genetic change."

These statements illustrate most clearly why we regard the coevolutionary approach as confusing. Unless one ignores (1) the history of natural selection, i.e., its cumulative effects on the genotype, (2) the integrity of genes from generation to generation, and (3) the various kinds of learning biases that result from the interaction of the organism's genetic materials with the environment during behavioral development," one cannot argue that cultural transmission is "distinct from genetics," that "the traits transmitted are non-genetic," or that phenotypes change "wholly independently of [past] genetic change."

Durham later argues that in his proposed process of "constrained microevolution ... both kinds of fitness, genetic fitness and cultural fitness, vary as a function of the phenotypes they help to create," If by "they" he means "both kinds of fitness," his statement is essentially meaningless: fitness cannot help to create phenotypes. Genetic fitness varies as a function of the phenotypes the genes help to create, but there is no parallel unit or underlying factor in culture that contributes to the phenotype. If by "they" he means "each kind of trait, genetic and cultural," then he is simply describing the process of organic evolution as it has always been known to biologists: selection always acts through phenotypes.

Durham defines cultural fitness as an attribute of cultural traits: "Instructions that are successfully 'handed down' for long periods of time 
. . . can be said to have high cultural fitness." In distinguishing directions of evolution of "genetic influence" and "cultural influence" on human phenotypes, however, he says that the latter "will similarly evolve in the direction of the available character state or states that maximize cultural fitness." Defining cultural fitness in terms of traits, and on the basis of their persistence, however, causes this statement to become nonsensical. The reason for this confusion, again, is that in the one case he speaks of genes and in the other case of traits; yet genes contribute to the evolution of both cultural and noncultural traits, and it is transmission of noncultural phenotypic traits, not genes, that ought to be compared to the transmission of cultural traits. Durham apparently uses the terms "cultural influence" as the parallel, in the causation of "cultural traits," to the influence of the genetic materials in the causation of any phenotypic trait. If this is his meaning, then at the very least he has omitted a third influence on the phenotype: that of the noncultural environment, which, equally with genes and culture, persists unchanged, often across multiple generations. It is a main part of our argument that this factor is consistently ignored in the dichotomies of the coevolutionary perspective.

Durham proposes five models of what he calls the "modes of interaction between biological and cultural evolution." His first model, "cultural mediation," concerns the selective pressures generated by culture as a part of the environment (e.g., changes in subsistence base introduce new selective pressures). There is little disagreement among current culture theorists that such cultural mediation takes place.

Durham's models of "genetic mediation" and "enhancement" are more problematical. In genetic mediation, "genetically inherited features [elsewhere called "biologically inherited" and "genetically determined" features] of the organisms affect either the ease or the reinforcement with which cultural traits are handed down through time" (p. 313). By genetic mediation Durham refers to the fact that an organism's genetic makeup will affect traits, such as learning biases, that influence cultural transmission. However, Durham persists in referring to "genetically determined" and "genetically inherited" features of the organism; this is a dichotomy we cannot accept. Since the organism's phenotype is the actual mediator, not its genes, the dichotomy ought to be between aspects of the phenotype that are acquired with cultural influence and aspects that are acquired without cultural influence. Durham also says that "genetic . . . determinants of cultural fitness are exogenous to the cultural system itself." His dichotomies cause him to ignore the fact that the existing cultural system is always a product of both cultural and noncultural influences in the past. Transmission defined as "cultural" may be seen as a vehicle of "other" 
means of transmission, or at most as an augmentation of them; it is not a substitute for them.

In Durham's "enhancement," "the fitnesses of alternative cultural instructions are governed by the cultural instructions so as to confer highest cultural transmissibility on character states of highest genetic fitness." "That which is 'good,' 'suitable,' 'appropriate,' etc. must also be adaptive even though the connection certainly need not be conscious. In the case of enhancement, unlike genetic mediation, the major determinants of cultural fitness are endogenous to the culture itself. Cultural transmission is selfregulating in this model, but the outcome will resemble or mimic the kind of adaptations produced by the natural selection of genotypes" (p. 314).

We believe that this distinction between genetic mediation and enhancement is also inappropriate. Durham's assertion that the transmission of cultural traits based on "cultural criteria (values, ideas, or beliefs)" creates a "self-regulating" process begs the issue. How are these "cultural criteria" of enhancement (i.e., values, etc.) initially established and maintained, independent of evolved "features of the organism [that] effect either the ease or the reinforcement with which cultural traits are handed down through time" (p. 305)? And what are the mechanisms, other than such features of the organism, that cause enhancement to "resemble or mimic the kinds of adaptations produced by natural selection"? Durham proposes no mechanisms for the selection of cultural criteria in his enhancement model (or for his "neutrality" or "opposition" models). Previously (Durham, 1979), however, he proposed four mechanisms for a process of "cultural selection" that he implied to be "completely distinct from the biological processes of inheritance" (1979: 40): (1) the "selective retention" of cultural traits resulting from learning biases in individuals that enhance their survival and reproduction; (2) the bias of "satisfaction" resulting from "the persistent, genetic selective advantage for a neurophysiology that is rewarded with sensory reinforcements and a feeling of 'satisfaction' for those acts likely to enhance survival and reproduction and those which produced unpleasant, distressing or painful feedback in response to potentially dangerous behaviors" (1979: 45; see also Ruyle, 1977); (3) biases in the structure of the brain and the CNS in general resulting from "the organic evolution of that organ" (1979: 45); (4) the "circumstantial bias" resulting from individuals with adaptive cultural traits producing more offspring, who by acquiring cultural traits via parental teaching increase the representation of those cultural traits.

None of these mechanisms is independent of the cumulative effects of natural selection on human learning abilities and propensities. Rather, they are all quite likely to be the results of such selection. 
Individuals accept or reject cultural traits; this is the "cultural selection" (e.g., Durham, 1979) or "psychological selection" (e.g., Cloak, 1975 ) process that determines the frequencies of cultural traits. Because individuals are born into a particular, existing cultural milieu and are shortlived, whereas cultural traits often persist and accumulate across generations, and because culture seems to be a group phenomenon, some culture theorists have concluded that individuals, even collectively, have trivial or random effects on the overall process of cultural evolution (e.g., White, 1959). Durham's distinction between enhancement and genetic mediation (i.e., cultural and noncultural mediation) parallels this superorganic perspective. Insofar as it refers to separate mechanisms for acquiring cultural traits, his dichotomy seems to us faulty because the cultural traits that exist in an individual's environment (including traits such as beliefs, ideas, or values that influence the transmission of other traits) are the cumulative results of past psychological selection by other individuals, always involving both cultural and noncultural mediation. We believe that the critical issue before culture theorists is: What are the evolved proximate mechanisms upon which adaptive learning is based?

Our attention, then, is turned to three questions that we believe represent the keys to eventual agreement and mutual understanding among the diverse culture theories from biology and the social sciences: (1) How can we characterize cultural traits so as to reflect their likelihood of being accepted or rejected? (2) How do the processes of acceptance or rejection take place? (3) How do the processes of acceptance or rejection relate to the presence, absence, and persistence of cultural traits, and to the overall forms and diversity of culture? The incredible complexity and unpredictability of human social environments are such that selection must have favored abilities continually to reprogram the mind's analysis of cultural traits (i.e., learning). The question, then, is what are the guidelines to this reprogramming that have been favored by natural selection? Such guidelines are likely to maximize: (1) acquisition of the most adaptive cultural traits, (2) abilities to utilize traits in appropriate circumstances, and (3) efficiency of data storage and assortment. We hypothesize that such effects are realized in human social environments by such shortcuts and cues as:

1. Imitating those who appear successful

2. Behaving oppositely or differently from those who appear unsuccessful (anti-imitation?)

3. Accepting advice and instruction from those with an interest in one's own success. These will include: (a) genetic relatives; (b) investors in reciprocity; (c) others who share the same interests (e.g., any group member, in some circumstances)

4. Viewing skeptically advice and instructions given by an individual with interests that conflict with one's own in regard to the topic being instructed. 
These simple mechanisms provide many possibilities for explanations of cultural phenomena. As a first example, imitation provides a likely basis not only for the acquisition of obviously useful behavior but also for the appearance and elaboration of fashion and its parallels: to appear like one who is successful can itself cause success. Second, all three kinds of social learning can lead to mistakes. What parent has not felt obliged to explain the long-term or overall disadvantages of the behavior of a rowdy, rude, drug-using, lawless, or shiftless individual who has momentarily become a hero to an offspring? Third, the interests of relatives or friends are not identical with one's own, leading to the probability of misuse of advice and instruction. Again, all parents probably expend some effort teaching their children how to know when to accept advice and instruction, and from whom to accept it.

Finally, the four kinds of social learning listed above are so phrased as to refer chiefly to success by individuals, as opposed to other individuals within the same groups. But the same vehicles will work when and if particular interests of individuals become synonymous with those of the group (or everyone else within it). In this way the paradox of culture as a group phenomenon and adaptiveness in the biological sense is resolved. Perhaps cultural evolution has involved much group extinction, not through resource depletion, but through intergroup competition (Alexander, 1971; Bigelow, 1969; Durham, 1976). In such cases one needs only to discover that the individual who survives even though his group loses is likely to lose compared to one who invests heavily in the effort to keep his group from losing. A very great deal of instruction apparently takes place around this issue in most human societies (see, e.g., Chagnon, 1977; LeVine and Campbell, 1972).

Chen et al. (this volume) analyze the similarity of cultural be 'iefs among nuclear family members and friends. Their study suggests that kinship is an important proximate mechanism in cultural transmission. Although it may be questionable to assume that when two individuals (e.g., father and son) share a cultural belief this implies transmission of that trait from one to the other, such studies may provide insights into basic learning patterns.

Chen et al. state that "without a parallel study of adopted children, even correlations of the type found here do not allow us to determine whether the transmission is cultural or genetic (p. 387). This implication of an either/or situation is potentially confusing. Chen et al. seem to be asking whether genetic differences between parents and offspring cause correlation of cultural beliefs to be absent. The relevant issue, as we see it, is whether there is a genetic contribution to tendencies such as learning more from individuals who in normal human social environments (i.e., similar to those in our evolutionary history) would be close relatives, imitating behaviors that appear successful, and so forth. 
To examine such hypotheses, additional questions need to be asked, such as: (a) Where historically new social situations are involved (e.g., the entertainment practices of youth in the Chen et al. study) and parents are not useful (i.e., adaptive) models, whom do individuals imitate? (b) Do individuals adopt or reject the cultural traits of their parents based on their perception of whether such traits have been useful and helpful for their parents? (c) What are parental, kin group, and peer group responses to the adoption of cultural traits (e.g., social pressure to conform to religious practices)? Such questions are difficult to answer adequately with survey data (cf. Griliches, 1957).

Pulliam (this volume) also addresses the issue of cultural transmission among relatives, hypothesizing that internal and external conflict are correlated with marital residence patterns. He starts with the basic assumption (examined by Chen et al.) that individuals tend to acquire cultural traits from proximally located individuals (household members). He further assumes that people who share cultural traits are more amicable towards one another. Noting that matrilocal residence brings together males (husbands) from different households, he hypothesizes that this results in greater internal conflict but less external conflict. In patrilocal societies he hypothesizes the opposite situation, less internal conflict but greater external conflict.

An obvious limitation of Pulliam's hypotheses is that many factors influence conflict and amicability other than the similarity of cultural traits that pertains among household members (e.g., see Paige and Paige, 1981). In addition, Pulliam considers only the effects of males; for females, his hypothesis predicts the opposite conflict situation.

More important, in our opinion, is Pulliam's failure to recognize that the variables he is dealing with, such as sharing ideas and residing in a household, are probably evolved proximate mechanisms for recognition of genetic relatives and/or reciprocators. Hence the ultimate reason for associations between idea sharing, residence, and conflict is likely to involve a history of kin selection and reciprocal altruism. The fact that humans (indeed, probably all social organisms) learn who their relatives are from cues such as proximity does not mean that such learning tendencies, and corresponding nepotistic behavior, are not products of natural selection.

Boyd and Richerson also propose a mechanism of cultural evolution based on the misconception that learning somehow decouples culture from biological adaptation. Their model of the group selection of "public goods" ignores relevant biological theories such as reciprocal altruism (Trivers, 1971), and is instead misdirected against the egoistic propositions of formalist economics, which are not synonymous with evolutionary theory. This error is evidenced by their statement that "sociobiology predicts that human behavior is fundamentally egoistic" (p. 335). To the "contrary, 
evolutionary theory predicts that sexual organisms such as humans have evolved to be fundamentally nepotistically altruistic.

Boyd and Richerson perceive the need for a group selection theory of cultural evolution because of their assumption that "social cooperation entails the production of public goods, and . . . in large groups rational, selfish individuals will not voluntary cooperate to produce public goods" (p. 337). This assumption is thoroughly refuted by Trivers (1971), Alexander (1975, 1979a, 1979b), Becker (1976), Durham (1976, 1979), and Irons (1979b).

\section{CONCLUSIONS}

We believe that a useful, complete theory of culture is simpler than the dichotomies promoted by the coevolutionary approach suggest. Culture can be regarded as an aspect of the environment into which each human is born and must succeed or fail, developed gradually by the succession of humans who have lived throughout history. We hypothesize that culture results from the inclusive-fitness-maximizing efforts of all humans who have lived. We think the evidence suggests that cultural traits are, in general, vehicles of genic survival, and that the heritability of cultural traits depends on the judgments (conscious and unconscious) of individuals with regard to their effects on the individual's inclusive fitness.

The challenge now before students of culture is to understand the proximate mechanisms, especially the ontogeny of learning biases, that result in the acquisition and transmission of cultural traits. How, for example, do we learn what constitutes an appropriate return on a social investment in different circumstances; i.e., what causes us to feel rewarded by, say, helping offspring who do not help us back, yet consistently to begrudge lesser expenditures to most others, or to feel cheated if we are not compensated for such expenditures immediately? We suggest that the answers to such questions lie in a few basic evolved learning tendencies.

\section{REFERENCES}

Alexander, R. D. (1971). The search for an evolutionary philosophy of man. Proceedings of the Royal Society of Victoria 84:99-120.

Alexander, R. D. (1975). The search for a general theory of behavior. Behavioral Science 20: $77-100$.

Alexander, R. D. (1977). Natural selection and the analysis of human sociality. In Goulden, C. E. (ed.), Changing Scenes in the Natural Sciences: 1776-1976, Bicentennial Symposium Monograph, Philadelphia Academy of Natural Sciences Special Publication No. 12, pp. 283-337.

Alexander, R. D. (1979a). Darwinism and Human Affairs, University of Washington Press, Seattle and London. 
Alexander, R. D. (1979b). Evolution, social behavior, and ethics. In Engelhardt, T. E., and Callahan, D. (ed.), The Foundation of Ethics and Its Relationship to Science, Vol. 4, Hastings Institute, Hastings-on-Hudson, N.Y.

Alexander, R. D., and Borgia, G. (1978). Group selection, altruism, and the levels of organization of life. Annual Review of Ecology and Systematics 9: 449-474.

Becker, G. S. (1976). The Economics of Human Behavior. Univ. of Chicago Press, Chicago.

Bigelow, R. S. (1969). The Dawn Warriors: Man's Evolution Toward Peace. Little, Brown, Boston.

Bonner, J. T. (1980). The Evolution of Culture in Animals. Princeton University Press, Princeton.

Boyd, R., and Richerson, P. J. (1976). A simple dual inheritance model of the conflict between social and biological evolution. Zygon 11(3): 254-262.

Cavalli-Sforza, L. L., and Feldman, M. W. (1981). Cultural Transmission and Evolution: A Quantitative Approach. Princeton University Press, Princeton, N.J.

Chagnon, N. A. (1977). Yanomamö: The Fierce People, 2nd ed. Holt, Rinehart \& Winston, New York.

Chagnon, N. A. (1979). Is reproductive success equal in egalitarian societies? In Chagnon, N. A., and Irons, W. G. (eds.), Evolutionary Biology and Human Social Behavior: An Anthropological Perspective, Duxbury Press, North Scituate, Mass.

Chagnon, N. A. (1981). Terminological kinship, genealogical relatedness and village fissioning among the Yanomamö Indians. In Alexander, R. D., and Tinkle, D. W. (eds.), Natural Selection and Social Behavior, Chiron Press, New York and Concord.

Chen, K-H., Cavalli-Sforza, L. L., and Feldman, M. W. (1982). A study of cultural transmission in Taiwan, Human Ecology 10: 375-392.

Cloak, F. T. (1975). Is a cultural ethology possible? Human Ecology 3: 161-182.

Daly, M., and Wilson, M. (1978). Sex, Evolution, and Behavior. Duxbury Press, North Scituate, Mass.

Daly, M., and Wilson, M. (1981). Abuse and neglect of children in evolutionary perspective. In Alexander, R. D., and Tinkle, D. W. (eds.), Natural Selection and Social Behavior, Chiron Press, New York and Concord.

Dawkins, R. (1976). The Selfish Gene. Oxford University Press, New York.

Dickemann, M. (1979). The reproductive structure of stratified human societies: a preliminary model. In Chagnon, N. A., and Irons, W. G. (eds.), Evolutionary Biology and Human Social Organization: An Anthropological Perspective, Duxbury Press, North Scituate, Mass.

Dickemann, M. (1981). Paternal confidence and dowry competition: a biocultural analysis of purdah. In Alexander, R. D. and Tinkle, D. W. (eds.), Natural Selection and Social Behavior, Chiron Press, New York and Concord.

Durham, W. H. (1976). Resource competition and human aggression, part I: A review of primitive war. Quarterly Review of Biology $51: 385-415$.

Durham, W. H. (1979). Toward a coevolutionary theory of human biology and culture. In Chagnon, N. A., and Irons, W. G. (eds.), Evolutionary Biology and Human Social Behavior: An Anthropological Perspective, Duxbury Press, North Scituate, Mass.

Durham, W. H. (1982). Interactions of genetic and cultural evolution: Models and examples. Human Ecology 10: 299-334.

Durkheim, E. (1938). The Rules of the Sociological Method, 7th ed., Free Press, Glencoe, Ill.

Flinn, M. V. (1981). Uterine vs. agnatic kinship variability and associated cousin marriage preferences: An evolutionary biological analysis. In Alexander, R. D., and Tinkle, D. W. (eds.), Natural Selection and Social Behavior, Chiron Press, New York and Concord.

Gould, S. J., and Lewontin, R. C. (1979). The spandrels of San Marco and the panglossian paradigm: A critique of the adaptationist programme. Proceedings of the Royal Society of London B 205: 581-593,

Griliches, Z. (1957). Hybrid corn: An exploration in the economics of technological change. Econometrica 25:501-522.

Hames, R. B. (1979). Relatedness and interaction among the Ye'kwana: A preliminary analysis. In Chagnon, N. A., and Irons, W. G. (eds.), Evolutionary "Biology and Human Social Behavior, Duxbury Press, North Scituate, Mass. 
Hamilton, W. D. (1964). The genetical evolution of social behavior, 1, II. Journal of Theoretical Biology $7:$ 1-52.

Harris, M. (1974). Cows, Pigs, Wars, and Witches: The Riddle of Culture. Random House, New York.

Irons, W. G. (1979a). Investment and primary social dyads. In Chagnon, N. A., and Irons, W. G. (eds.), Evolutionary Biology and Human Social Behavior: An Anthropological Perspective, Duxbury Press, North Scituate, Mass.

Irons, W. G. (1979b). Cultural and biological success. In Chagnon, N. A., and Irons, W. G. (eds.), Evolutionary Biology and Human Social Behavior, Duxbury Press, North Scituate, Mass.

Kroeber, A. L. (1917). The superorganic. American Anthropologist 19: 163-213.

LeVine, R. A., and Campbell, D. T. (1972). Ethnocentrism: Theories of Conflict, Ethnic Attitudes, and Group Behavior, John Wiley, New York.

Levi-Strauss, L. (1949). Les Structures élémentaires de la Parenté. Plon, Paris.

Lewontin, R. C. (1970). The units of selection. Annual Review of Ecology and Systematics 1: $1-18$.

Lumsden, C. J., and Wilson, E. O. (1981). Genes, Mind, and Culture. Harvard Univ. Press, Cambridge, Mass. and London, England.

Mundinger, P. L. (1980). Animal cultures and a general theory of cultural evolution. Ethology and Sociobiology 1: 183-223.

Paige, K. E., and Paige, J. M. (1981). The Politics of Reproductive Ritual, Univ. of Calif. Press, Berkeley.

Parsons, T. (1954). Essays in Sociological Theory, Rev. ed. Free Press, Glencoe, Ill.

Pulliam, H. R. (1982). A social learning model of conflict and cooperation in human societies. Human Ecology 10:363-374.

Pulliam, H. R., and Dunford, C. (1980). Programmed to Learn: An Essay on the Evolution of Culture. Columbia University Press, New York.

Rappaport, R. (1968). Pigs for the Ancestors: Ritual in the Ecology of a New Guinea People. Yale University Press, New Haven.

Richerson, P. J., and Boyd, R. (1978). A dual inheritance model of the human evolutionary process, I. Basic concepts and a simple model. Journal of Social and Biological Structures 1: 127-154.

Ruyle, E. E. (1973). Genetic and cultural pools: Some suggestions for a unified theory of biocultural evolution. Human Ecology 1(3): 201-215.

Ruyle, E. E. (1977). Comment on "The adaptive significance of cultural behavior." Human Ecology 5(1): 53-55.

Sahlins, M. D. (1976a). The Use and Abuse of Biology: An Anthropological Critique of Sociobiology. University of Michigan Press, Ann Arbor.

Sahlins, M. D. (1976b), Culture and Practical Reason. University of Chicago Press, Chicago.

Schneider, D. M. (1972). What is kinship all about? In Reinig, P. (ed.), Kinship Studies in the Morgan Centennial Year, Anthropological Society of Washington, D.C.

Steward, J. H. (1955). Theory of Culture Change: The Methodology of Multilinear Evolution. University of Illinois Press, Urbana, Ill.

Symons, D. (1979). The Evolution of Human Sexuality. Oxford Univ. Press, New York.

Trivers, R. L. (1971). The evolution of reciprocal altruism. Quarterly Review of Biology 46: $35-57$.

Vayda, A. P. (1969). Expansion and warfare among swidden agriculturalists. In Vayda, A. P. (ed.), Environment and Cultural Behavior, Doubleday, Garden City.

West-Eberhard, M. J. (1975). The evolution of social behavior by kin selection. Quarterly Review of Biology 50(1): 1-53.

White, L. A. (1949). The Science of Culture: $A$ Study of Man and Civilization. Farrar, Straus \& Giroux, New York (Reprinted in (1969).

White, L. A. (1959). The Evolution of Culture: The Development of Civilization to the Fall of Rome. McGraw-Hill, New York.

Williams, G. C. (1966). Adaptation and Natural Selection. Princeton University Press, Princeton. 
Winterhalder, B. P., and Smith, E. A. (eds.), (1981). Hunter-Gatherer Foraging Strategies: Ethnographic and Archaeological Analyses. University of Chicago Press, Chicago (forthcoming).

Wynne-Edwards, V. C. (1962). Animal Dispersion in Relation to Social Behavior. Oliver \& Boyd, Edinburgh. 